\title{
School Administrators and Teachers Identification Mechanism of Students with Behavioral Problems in Secondary Schools: South West Ethiopia
}

\author{
Aminu Jibril Arfasa ${ }^{1} *$; Jaffer Lola Dano ${ }^{2}$ \\ ${ }^{1}$ Department of Psychology, College of Education and Behavioral Sciences, Jimma University, Ethiopia \\ ${ }^{2}$ Department of Special Needs and inclusive education, College of Education and Behavioral Sciences, Jimma \\ University, Ethiopia \\ *aminujibri145@yahoo.com \\ http://dx.doi.org/10.18415/ijmmu.v6i3.940
}

\begin{abstract}
The purpose of the study was to investigate school administrators and teachers identification mechanism of students with behavioral problems in secondary schools. The research method was descriptive survey method and quantitative research design was used. The researcher used both primary and secondary data as a source. The primary data was gathered through questionnaire while the secondary sources were from written documents. Study populations were school administers (school principals, vice school principals and unit leaders) and teachers of secondary school of south west Ethiopia. The sampling technique used to draw sample from study population was multi stage random sampling technique. First stage 5 zones in south western Ethiopia were selected. On the second stage, from each zones 3 woredas/twon and one secondary school in each woredas were selected. The schools administers of selected schools were selected by purposive sampling and teachers were selected by random sampling techniques. All school administers of selected secondary schools 45 schools administers (school principals, vice school principals and unit leaders) selected purposively and 420 teachers selected by simple random sampling techniques. The instruments of data collection were Likert scale closed-ended self- administered questionnaire for teachers and school administers. To check the reliability of instrument pilot testing was conducted on 30 individuals. Cronbach alpha calculated result showed that reliability coefficient was 0.83 . Validation of the instruments was done by using experts' review and discussion. Based on experts comments irrelevant items were discarded and some ambiguous items were modified. The current study was used quantitative methods of data analysis. The analysis of data was done using percentage, mean and standard division while analysis of qualitative data was done by thematic analysis methods. The result of the study indicated both teachers and school administers were not used standardized tools to identify student's behavioral problem. The mean scores of teachers $(\mathrm{M}=3.40$ with $\mathrm{Sd}$ 1.24) and school administers $(\mathrm{M}=4.10$ with $\mathrm{Sd}=1.01)$ agreed that most of the time they identify students behavioral problems by office discipline and/or classroom minor behavioral records and attendance the methods. In addition, both teachers and school administers reported that they identified students behavioral problems based on information get from peers, other staff teachers and parents. Both teachers and school administers perceived that internalized behavioral problems such initiation of aggressive behaviors, harassments, lack of empathy and externalized behavioral problems external behavioral problems such as frequent absences from school or poor performance in school, exhibits
\end{abstract}


persistent patterns of stealing and lying. From these results, it was recommended that to reduce student's behavioral problems the researcher recommended that the school principals, teachers and other stakeholders should set some sorts of rules and regulations specific to the school with the active involvement of the students, in addition to the rules and the regulations of the country.

Keywords: Behavioral Problems; Identification Mechanism; School Administers

\section{Introduction}

\subsection{Background}

Adolescent behavioral problems are considered as any repeated patterns of behavior or perception that interfere with normal learning or engagement in pro-social interactions with peers and school community Smith and Fox (2003). The causes of adolescent behavioral problems may vary originate from several sources. Some of them include poor parental supervision coupled with poor academic performance; risk in the family and the school the greater the likelihood of early-onset offending (Loeber and Farrington, 1998). Students with Emotional and Behavioral Disorder are often characterized by disruptive social behaviors and exhibit poorer attendance rates, higher drop-out rates, and higher rates of grade retention "than any other disability category (Lane, 2007).

Student behavioral problems, can disrupts the teaching-learning process creates psychological and physical discomfort harms property and with far reaching implications towards the achievement of educational goal (Morongwa, 2010). Maintaining good discipline and timely intervening behavioral problems of students in the class as well as in the school is one of the most important aspects of teaching. Because of the uncontrollable behavior of students lessens the quality of education and hinders the teaching learning processes (Center for Mental Health in Schools, 2008).

Appropriate academic, social, and behavioral skills allow students to become part of the class, the school, and the community. For students to be successful in school settings, their classroom behavior must be consistent with teachers' demands and academic expectations and must promote their learning and socialization with peers (Mental Health In school program and policy analyst, 2015). According to Hanover Research (2013), Peer-assisted learning strategies, class-wide peer tutoring, and selfmanagement interventions have been recognized by scholars of Emotional and Behavioral Disorder as effective in increasing levels of student engagement and achievement.

Too many teachers know too little about how best to understand, identify, support and guide students who manifest commonplace behavior, learning, and emotional problems (Center for Mental Health in Schools, 2008). Teachers can access a wealth of information sources when attempting to identify the cause of misbehavior: e.g., student work products, direct observation; interviews (with the student, other teachers, parents), etc. However, when trying to understand misbehavior, educators may be too quick to choose global explanations that fit preconceptions of the student--but are not supported by the data (Christ, 2008).

In school setting if there is well developed school rules with applicable to identify and intervene student problems, teachers have greater success in managing the full spectrum of student misbehaviors when they respond flexibly--evaluating each individual case and applying strategies that logically address the likely cause(s) of that student's problem. When an educator can identify the probable function sustaining a particular set of behaviors, the teacher has confidence (Marzano, Marzano, \& Pickering, 2003). When students are involved in the development of the rules, they are more likely to adhere to them and understand why they have been put into place (Dawn, 1998). 
To bring quality education, it need the cooperation of Classroom teachers, paraprofessionals, school psychologists, school administrators and other school personnel play important roles in developing and implementing strategies that embrace those characteristics (Mary, David, Cynthia, and Thomas, 2000).

Teachers, parents and the school administration are expected to play a great role for the academic and social behavioral success of children with behavioral problem. When teachers are aware of the needs of individual difference, they can build in methods for helping each student get their needs met strategies to address the problem behavior of young children (Richard, 2007:111).

It is believed that when school have rules, resources, and the structure of a comprehensive program to work on how to assess and intervene student behavioral problems good things happen, that improve academic achievement, students take more demanding courses, students develop and use career plans, and schools have more positive climates (Day, 2004).

\subsection{Statements of the Problems}

When a student displays challenging behaviors, it can be easy to fall into the trap of simply wishing that those misbehaviors would go away. The point of a behavioral intervention, however, should be to expand the student's repertoire of pro-social, pro-academic behaviors - rather than just extinguishing aberrant behaviors. By selecting a positive behavioral goal that is an appropriate replacement for the student's original problem behavior, the teacher reframes the student concern in a manner that allows for more effective intervention planning (Batsche, Castillo, Dixon, \& Forde, 2008).

Teachers and paraprofessionals often are the first to recognize a student's lack of success with assignments, and his or her continuous problems with peer or adult relationships (Mary, David, Cynthia, and Thomas, 2000). To improving instruction, it is evident that teachers need to work closely with other teachers and school personnel, as well as with parents, professionals-in-training, volunteers, and so forth. Collaboration and teaming are key facets of addressing barriers to learning. (Center for Mental Health in Schools, 2008:11).

Teachers skilled in classroom management and assisting students with behavioral problems are able to respond appropriately to just about any behavior that a student brings through the classroom door. The real secret of educators who maintain smoothly running classrooms with minimal behavioral disruptions is that they are able to view problem student behaviors through the lens of these seven 'big ideas' in behavior management: Check for academic problems, Identify the underlying function of the behavior, Eliminate behavioral triggers, Redefine the behavioral goal as a replacement behavior, Rule out the most likely causes for misbehavior first, Be flexible in responding to misbehavior, and Manage behaviors through strong instruction (Jim Wright, 2013:1).

Most schools have some programs and services that fit along the entire continuum. However, interventions at each level are not integrated and are not well connected. Moreover, the tendency to focus mostly on the most severe problems has skewed the process so that too little is done to prevent and intervene early after the onset of a problem. One result of this is that public education has been characterized as an institution that "waits for failure" before intervening. So, the current study was intended to investigate adolescent behavioral problems identification and intervention mechanism used by teachers and school administer among south west Ethiopia secondary schools by answering the following research questions. 


\subsection{Research Questions}

1. What identification mechanisms do school administers and teachers employ to identify students with behavioral Problems?

2. What are the dominant students behavioral problems identified by school administrators and teachers point of view?

\subsection{Objective of the study}

\section{General objective}

General objective of the study is to assess school administrators' and teachers identification and intervention mechanism of students with behavioral problems

\section{Specific objective}

1. To investigate identification mechanisms that school administers and teachers employ to identify students with behavioral problems

2. To assess the dominant students behavioral problems from school administrators and teachers point of view

\subsection{Significances of the study}

This research will have a number of importance which will contribute to gather information on the way school rules and classroom teachers understand and intervening adolescent problematic behaviors that interfere student's academic achievement. Specifically the result would help any organization working on identifying and intervening student's academic, social, psychological and relationship problems. As school rules and classroom teachers are keys in understanding, identifying and intervention their student's behavioral problems, the results of this study would help to identify different strategies used by teachers to help students suffer by problematic behaviors. Moreover, this study would shed light on the problems from school rules and regulation working to treat student with problematic behavior and identify the strategies used by teachers in identifying and intervening the behavioral problems is really contributing in overcoming the problems.

\section{Research Methodology}

\subsection{The Research Method}

The research method was descriptive survey method. Descriptive survey used to describe the way how school administers and teachers identify students with behavioral problems in their respective schools. Descriptive research is a type of quantitative research that involves making careful descriptions of phenomena, concerned primarily with determining " what is".

\subsection{Study Design}

The current study was used quantitative research design. This design is help to gather data at a particular point in time with the intention of describing the nature of existing conditions, or determining the relationships that exists between specific events.

\subsection{Sources of Data}

The researcher used both primary and secondary data as a source. The primary data was gathered through questionnaire while the secondary sources were from written documents as to have some 
background information about the issues. Documents like books, journals, research papers, published and unpublished materials and annual abstracts were examined.

\subsection{Study Population}

Study populations were school administers (school principals, vice school principals and unit leaders) and teachers of secondary school of south west Ethiopia.

\subsection{Sample and Sampling Techniques}

The sampling technique used to draw sample from study population was multi stage random sampling technique. First stage 5 zones in south western Ethiopia were selected. The selected zones were Iluababor zone, West Wollega zone, Skeka zone, Bunno Bedele and Jimma zone. On the second stage, from each zones 4 woredas/twon were selected. Among secondary schools in selected weredas/town one secondary school were selected by simple random methods. The schools administers of selected schools were selected by purposive sampling and teachers were selected by random sampling techniques. All school administers of selected school were taken as study sample. Accordingly, the samples of the study were 45 school administers (school principals, vice school principals and unit leaders) and 420 teachers.

\subsection{Instruments of Data Collection}

The questionnaires for this study was containing mainly close ended and some open ended items. The questionnaires prepared by using Likert scale. The instrument was mainly consisting of questions about how secondary school administers and teachers identify student's behavioural problems in their schools. The close-ended part of the questionnaire used in this study was a Likert Scale questionnaire. Likert scale requires an individual to respond to a series of statements by indicating whether are strongly agrees (5), agrees (4), is undecided (3), disagrees (2), or strongly disagrees (1).

\subsection{Reliability and validity of instruments}

The instrument of data collection was evaluated through conducting pilot test before final data was collected. The pilot test was helps to check the reliability of instrument. The pilot test was conducted with 30 participants to check the internal consistency reliability of the instruments. The total reliability of instrument was $(\mathrm{r}=.83)$. This implies that instruments have very good internal constancy reliability to measures what it intended to measure. After preparing the instruments for data collection; validation of the instruments was done using experts' review and discussion. In addition to experts' review and discussion, forward and backward translation would be made to minimize meaning differences in the two languages.

\subsection{Data analysis}

The researcher is used different statistical measurement to analyze the obtained data from respondents. Data obtained from questionnaire had been analyzed quantitatively using SPSS version 20 by descriptive statistics using percentage, mean and standard deviation.

\section{Results and Discussion}

The aim of the current study was to investigate the school administrators' and teachers identification mechanism of students with behavioral problems in south west Ethiopia secondary schools. In this section data generated from the current study is presented, interpreted and discussed in line with research question. 


\subsection{Demographic Characteristics of Study Participants}

Data analysis for this study was based on the information obtained from 420 teachers and 45 schools administers. Among selected zone of south west Ethiopia three schools were selected from each zone. From all schools selected one principal, one vice principal and unit leader were obtained.

Table 1. Demographic data of teacher's participants administers

\begin{tabular}{llllll}
\hline & Teacher & Number & Percent & \multicolumn{2}{c}{ School administers } \\
& & Number & Percent \\
Gender & Male & 296 & 70.4 & 32 & 71 \\
& Female & 124 & 29.6 & 13 & 29 \\
& Total & $\mathbf{4 2 0}$ & $\mathbf{1 0 0}$ & $\mathbf{4 5}$ & $\mathbf{1 0 0}$ \\
Age & $20-25$ & 82 & 19.4 & 8 & 19.4 \\
& $26-29$ & 120 & 26.9 & 12 & 26.9 \\
& $30-33$ & 145 & 35.2 & 16 & 35.2 \\
& $34-37$ & 37 & 9.3 & 5 & 9.3 \\
& $38-41$ & 18 & 4.6 & 2 & 4.6 \\
& 42 and above & 18 & 4.6 & 2 & 4.6 \\
\hline
\end{tabular}

As shown in table 1, among the 420 teacher respondents in the study, 296 (70.4\%) were males while the remaining $124(29.6 \%)$ were females. The major age of teachers participant were between3033145 (35\%), while few 18(4.6\%) teachers were above 42 age. Majority of teachers participants 342 $(81.5 \%)$ were first-degree holders, 58(13.9\%) were secondary degree holders while $16(3.7 \%)$ were diploma holders. Also as shown in table 1, among the 45 school administer respondents in the study, 32 (71.4\%) were males while the remaining $13(29 \%)$ were females. The major age of school administers participants were between30- $3316(36 \%)$, while few $2(4 \%)$ teachers were above 42 age. Majority of school administers participants $36(82 \%)$ were first-degree holders, 6(13.9\%) were secondary degree holders while $2(4 \%)$ were diploma holders.

\subsection{Identification Mechanisms Do Teachers and School Administers Employ to Identify Students with Behavioral Problems}

Table 2. Identification mechanisms do teachers and School administers employ to identify students with behavioral Problems

\begin{tabular}{|c|c|c|c|c|c|c|c|}
\hline \multirow{2}{*}{$\begin{array}{l}\mathbf{S} \\
\mathbf{N}\end{array}$} & \multirow[t]{2}{*}{ Statements } & \multicolumn{3}{|c|}{ Teachers } & \multicolumn{3}{|c|}{ School Administers } \\
\hline & & $\mathbf{N}$ & Mean & Std & $\mathbf{N}$ & Mean & Std \\
\hline 1. & $\begin{array}{l}\text { By using standardized problems behavior Screening } \\
\text { Instrument }\end{array}$ & 420 & 0 & 0 & 45 & 0 & 0 \\
\hline 2 & $\begin{array}{l}\text { By using problems behavior screening instruments } \\
\text { developed by school team teachers }\end{array}$ & 420 & 1.29 & 1.28 & 45 & 1.70 & 1.29 \\
\hline 3 & $\begin{array}{l}\text { By identifying office discipline and/or classroom minor } \\
\text { behavioral records, attendance }\end{array}$ & 420 & 3.40 & 1.24 & 45 & 4.10 & 1.04 \\
\hline 4 & $\begin{array}{l}\text { By direct observation of students who show problematic } \\
\text { behavior in class room and outside of class room in } \\
\text { school compound }\end{array}$ & 420 & 4.29 & 1.30 & 45 & 4.87 & 1.25 \\
\hline 5 & $\begin{array}{l}\text { Get information regarding repeated conflicting, arguing, } \\
\text { isolating behavior of students from peers, others staff } \\
\text { teachers and from parents. }\end{array}$ & 420 & 2.90 & 1.38 & 45 & 2.96 & 1.62 \\
\hline & Total & 420 & 11.88 & 5.2 & 45 & 13.63 & 5.2 \\
\hline
\end{tabular}


Table 2 above shows the Identification mechanisms do teachers and school administers employ to identify students with behavioral Problems. For the question whether the teachers and school administers identify their student's behavioral problems by using standardized problems behavior screening instrument, both teachers and school administers were not use the methods. This implies that all secondary schools of study area were not develop or adopt standardize problems identification mechanisms in their schools. This results was the same with Center for Mental Health in Schools, (2008) too many teachers know too little about how best to understand, identify, support and guide students who manifest common place behavior, learning, and emotional problems. The mean scores of teachers $(\mathrm{M}=$ 3.40 with $\mathrm{Sd} 1.24)$ and school administers $(\mathrm{M}=4.10$ with $\mathrm{Sd}=1.01)$ agreed that they frequently identify students behavioral problems by office discipline and/or classroom minor behavioral records and attendance. Even if both teachers and school administers were used this mechanisms, it is not help to dig out deep rooted behavioral problems. Maintaining good discipline and timely intervening behavioral problems of students in the class as well as in the school is one of the most important aspects of teaching. Because of the uncontrollable behavior of students lessens the quality of education and hinders the teaching learning processes (Center for Mental Health in Schools, 2008).

For question whether secondary schools teachers and administers were developed and use problems identification tools, the mean teachers $(\mathrm{M}=1.29)$ with a standard deviation of (SD 1.28) and the mean school administers $(M=1.70)$ with a standard deviation of (SD 1.29) were agreed as they used school based developed students behavioral problems identification tools. The mean scores of both teachers and school administers was below average which implies most of secondary schools in study area teachers and administers were not develop school based behavioral problems identification. This indicates that attention not given on this issues both by teachers and school administers. On the other hand, the mean scores of teachers $(\mathrm{M}=4.29$ with $\mathrm{Sd}=1.30)$ and school administers $(\mathrm{M}=4.87$ with $\mathrm{Sd}=$ 1.28) were agreed that they identify their students behavioral problems by direct observation in classroom and in school compound. This indicate that most of secondary schools teachers and administers in study area were used direct observation as means to identify students behavioral problems. It is usually sufficient to describe the behavior without inference, identify emotional responses, and appreciate the effect of the behavior's consequences (Witt, Daly, \& Noell, 2000). At times understanding the variety of causes that could contribute to disruptive behavior in the classroom can help you select the most appropriate solution (Sally, Kuhlen schmidt, Lois, and Layne, 1999).

For the question whether secondary school teachers and students identify their students behavioral problems based on information get from peers, other staff teachers and parents, the mean scores of teachers was $(\mathrm{M}=2.90$ with $\mathrm{Sd}=1.38)$ and the mean scores of school administers was $(\mathrm{M}=1.96$ with $\mathrm{Sd}=1.62$ ) respectively. This implied that both teachers and school administers were get information from others people as means of identifying students behavioral problems. This results similar with Christ, (2008) teachers can access a wealth of information sources when attempting to identify the cause of misbehavior: e.g., student work products, direct observation; interviews (with the student, other teachers, parents), etc. However, when trying to understand misbehavior, educators may be too quick to choose global explanations that fit preconceptions of the student. When an educator can identify the probable function sustaining a particular set of behaviors, the teacher has confidence that interventions selected to match the function will be correctly targeted and therefore likely to be effective. 


\subsection{Dominant Students Behavioral Problems from School Administrators and Teachers Point of View}

Table 3. Dominant characteristics of students with behavioral Problems for teachers

\begin{tabular}{|c|c|c|c|c|c|c|c|}
\hline & \multirow[t]{2}{*}{ Statements } & \multicolumn{3}{|c|}{ Teachers } & \multicolumn{3}{|c|}{ School Administers } \\
\hline & & $\mathbf{N}$ & Mean & Std & $\mathbf{N}$ & Mean & Std \\
\hline 1 & Initiation of aggressive behavior & 420 & 4.22 & 1.39 & 45 & 4.61 & 1.22 \\
\hline 2 & A display of harassment, threatening, & 420 & 3.23 & 1.3 & 45 & 3.24 & 1.12 \\
\hline 3 & $\begin{array}{l}\text { Showing little empathy and little concern for feelings, } \\
\text { wishes, and wellbeing of others. }\end{array}$ & 420 & 2.46 & 1.5 & 45 & 2.77 & 1.34 \\
\hline 4 & Lack of feelings of guilt or remorse. & 420 & 2.18 & 1.2 & 45 & 2.05 & 1.10 \\
\hline 5 & Blame others for their own misdeeds. & 420 & 1.83 & 1.3 & 45 & 1.93 & .91 \\
\hline 6 & Absences from school or poor performance & 420 & 3.29 & 1.3 & 45 & 3.77 & 1.41 \\
\hline 7 & stealing, lying, and/or cheating & 420 & 4.93 & .91 & 45 & 4.61 & 1.22 \\
\hline 8 & Runs around room, Ignores teacher & 420 & 4.16 & 1.01 & 45 & 4.77 & 1.34 \\
\hline \multirow[t]{2}{*}{9} & Bring different substance and sharp materials to school & 420 & 4.77 & 1.41 & 45 & 4.05 & 1.10 \\
\hline & Total & 420 & 39.58 & 15.8 & 45 & 39.18 & 14.2 \\
\hline
\end{tabular}

There are 5 likert scale ranked in the scale of never, seldom, sometimes, Often and very often, showing the behavioral problems of students.

\subsubsection{Internalized Behavioral Problems}

Regarding to initiation of aggressive behavior and reacting aggressively to others and properties the mean scores of both teachers and school administrators were high which was $(\mathrm{M}=4.22)$ with standard division ( $\mathrm{STD}=1.39)$ and that of school administers was $(\mathrm{M}=4.61)$ with standard division $(\mathrm{STD}=1.22)$ respectively. These mean scores showed that both teachers and school administers perceived initiation of aggressive behaviors toward others and properties were type's dominant behavioral problems of students in their respected schools. The most commonly observed behavioral functions in classrooms are escape/avoidance and peer or adult attention (Packenham, Shute, \& Reid, 2004). According to Mary, David, Cynthia, and Thomas, ( 2000) to bring quality education, it need the cooperation of Classroom teachers, paraprofessionals, school psychologists, school administrators and other school personnel play important roles in developing and implementing strategies that embrace those characteristics.

Concerning student's behavioral problems related with displaying of harassment, threatening, or unapproachable behavior the mean scores of both teachers and school administrators were similar. The teachers and school administrators mean scores of students behavioral problems related with displaying of harassment, threatening, or unapproachable behavior were for teachers $(\mathrm{M}=3.23)$ with standard division $(\mathrm{STD}=1.37)$ and that of school administers was $(\mathrm{M}=3.24)$ with standard division $(\mathrm{STD}=1.12)$ respectively. Both teachers and school administers mean scores implies that display of harassment, threatening, or unapproachable behavior was one of dominant behavioral problems of students of their schools. It is believed that when school have rules, resources, and the structure of a comprehensive program to work on how to assess and intervene student behavioral problems good things happen, that improve academic achievement, students take more demanding courses, students develop and use career plans, and schools have more positive climates (Day, 2004).

Regarding e students behavioral problems related with show little empathy and little concern for feelings, wishes, and wellbeing of others, the mean scores of both teachers and school administrators were less. The teachers mean scores of students behavioral problems related with show little empathy and little 
concern for feelings, wishes, and wellbeing of others was $(\mathrm{M}=2.46)$ with standard division $(\mathrm{STD}=1.53)$ and that of school administers was $(\mathrm{M}=2.77)$ with standard division $(\mathrm{STD}=1.34)$ respectively. This implied that majority of both teachers and school administers in study area were not perceived showing little empathy and little concern for feelings, wishes, and wellbeing of others as behavioral problems. This results may be both teachers and school administers were not have professional training how to identify students internal behavioral problems. When teachers are aware of the needs of individual difference, they can build in methods for helping each student get their needs met strategies to address the problem behavior of young children (Richard, 2007:111).

\subsubsection{Externalized Behavioral Problems}

As table above show both teachers and school administrators mean scores of the external behavioral problems of students such as frequent absences from school or poor performance in school, exhibits persistent patterns of stealing, lying, and/or cheating, runs around room, ignores teacher and does not follow directions and bring different substance and bringing sharp materials to school were among main behavioral problems observed in their school. These mean sores of both teachers and school administers were indicated in frequent absences from school or poor performance in school mean scores of teachers $(M=3.29$ with $\mathrm{Sd}=1.35$ ) and mean score of school administers $(\mathrm{M}=3.77$ with $\mathrm{Sd}=1.44)$, exhibits persistent patterns of stealing, lying, and/or cheating mean scores of teachers $(\mathrm{M}=3.93$ with $\mathrm{Sd}=$ .91 ) and mean score of school administers $(\mathrm{M}=4.61$ with $\mathrm{Sd}=1.22)$, runs around room, ignores teacher and does not follow directions and bring different substance mean scores of teachers $(\mathrm{M}=3.98$ with $\mathrm{Sd}=$ $1.40)$ and mean score of school administers $(\mathrm{M}=3.24$ with $\mathrm{Sd}=1.22)$ and bringing sharp materials to school mean scores of teachers $(M=4.77$ with $\mathrm{Sd}=1.41)$ and mean score of school administers $(\mathrm{M}=4.05$ with $\mathrm{Sd}=1.10$ ) respectively. The correlation between classroom misbehavior and deficient academic skills is high (Witt, Daly, \& Noell, 2000). Teachers should, therefore, routinely assess a student's academic skills as a first step when attempting to explain why a particular behavior is occurring. Lane, (2007) revealed that students with emotional and behavioral disorder are often characterized by disruptive social behaviors and exhibit poorer attendance rates, higher drop-out rates, and higher rates of grade retention "than any other disability category . Externalizing behavior problems can intensify during this period when peer influences can lead to rule breaking behavior such as delinquent and antisocial behaviors, substance use, and in some cases, gang involvement and drug dealing (Hann \& Borek, 2001). Lane, (2007) also mentioned that students with Emotional and Behavioral Disorder are often characterized by disruptive social behaviors and exhibit poorer attendance rates, higher drop-out rates, and higher rates of grade retention "than any other disability category.

\section{Conclusions}

The majority of identification mechanisms of students behavioral problems by teachers and School administer were employs to identify students with behavioral Problems. For the question whether the teachers and school administers identify their students using standardized problems behavior Screening Instrument; the show that zero (0) mean scores of both teachers and school administers. This result revels that both teachers and school administers were never used standardized problems behavior Screening Instrument to identify their student's behavioral problems.

Direct observation mechanisms as tools of identification of students who show problematic behavior in class room and outside of class room in school mean score identification mechanism of teachers and school administers were positive. Therefore, both teachers and school administers were used direction observation of students behavior in classroom and outsides of classroom as identification mechanisms of their students behavior problems. 
Majority teachers and school administers mean scores of the externalized students behavioral problems such as responded Initiation of aggressive behavior and reacting aggressively to others and properties, frequent absences from school or poor performance in school, exhibits persistent patterns of stealing, lying, and/or cheating, runs around room and etc. However, both teachers and school administers of study participants were not considered student's internal behavioral problems such as internal feeling, fantasy, and day dreaming. This may lack of skills and techniques how to identify students internalized behavioral problems.

Clear guidelines/rules and enforce rules, teaching new behavior and social skills and Create positive teacher-learner relationships are perceived by majority of teachers and School administration techniques they used to intervene students behavioral problems while both teachers and school administration responded that they were not assist their students referring them to professional workers like guidance and counseling and medical doctors. This may due to lack of professionals like guidance and counseling services in their schools.

\section{Recommendations}

Based on the finding of this study, the following recommendations are forwarded:

* Most schools teachers and administration responded as their schools never used either standardized screening to identify students' behavioral problems. This may due to lack standardized test in their schools. So, ministry of education and concerned bodies should prepare and distribute national student's behavioral problems screening tools.

* To reduce student's behavioral problems the researcher recommended that the school principals, teachers and other stakeholders should set some sorts of rules and regulations specific to the school with the active involvement of the students, in addition to the rules and the regulations of the country.

* Promote autonomy enforce rules and Consistent manner are among the techniques used to manage students' behavioral problems. Of course improving and expanding and counseling services to help the misbehaved students should come first before taking any action.

\section{References}

Burns, M. K., VanDerHeyden, A. M., \& Boice, C. H. (2008). Best practices in intensive academic interventions.

Center for Mental Health in Schools. (2008). Enhancing classroom approaches for addressing barriers to learning: Classroom-focused enabling. Los Angeles, CA: Author. http://smhp.psych.ucla.edu.

Christ, T. (2008). Best practices in problem analysis. In A. Thomas \& J. Grimes (Eds.), Best practices in school psychology V (pp. 159-176). Bethesda, MD: National Association of School Psychologists.

Dawn, R. (1998). Classroom Behavioural Strategies and Interventions: Towards Inclusion: Tapping Hidden Strengths.

Day, S. X., (2004). Theory and Design in Counseling and Psychotherapy. Boston,NY: Houghton Mifflin Company. 
Dekovic, M. (1999), Risk and protective factors in the development of problem behavior during adolescence, Journal of Youth and Adolescence, 28(6), 667-685.

Department of Health and Children (2006), A Vision For Change, Report of the Expert Working Group on Mental Health Policy, Stationary Office, Dublin.

Hall, D. \& Elliman, D. (ed) (2003), Health for All Children (4 th ed.), Oxford University Press, Oxford.

Hann, D. \& Borek, N. (2001), Taking Stock of Risk Factors for Child/Youth Externalising Behaviour Problems, National Institute of Mental Health.

Hanover Research, (2013), Effective Programs for Emotional and Behavioral Disorders.

Jim Wright, (2013). How the Common Core Works' Series: How To: Identify the Big Ideas to Guide Behavior Management. www.interventioncentral.org.

Lane, K, L. (2007). "Identifying and Supporting Students at Risk for Emotional and Behavioral Disorders within.

Loeber, R., and Farrington, D.P., eds. 1998. Serious and Violent Juvenile Offenders: Risk Factors and Successful Interventions. Thousand Oaks, CA: Sage Publications, Inc.

Mary, M. Q, David, O, Cynthia, W, Thomas, H, and Beth, De. B. (2000). Educational Strategies for Children with Emotional and Behavioral Problems: Center For Effective Collaboration And Practice American Institutes For Research: Published by Center for Effective Collaboration and Practice American Institutes for Research Washington, DC.

Mental Health In school program and policy analyst, (2015), Introductory Packet Conduct and behavioral problems.

Morongwa C, M. (2010). The Impact of Disciplinary Problems on Educator Morale In Secondary Schools and Implication.

Richard, T. S,( 2007). IOSIE: A Method for Analyzing Student Behavioral Problems: Analyzing Student Behavioral Problems: Vol. 80, No. 3. Heldref Publications.

Riordan, S., (2001), Supporting Parenting: A Study of Parent's Support Needs,CSER: Dublin.

Sally L. Kuhlenschmidt, Lois E. Layne.( 1999). Strategies For Dealing With Difficult Behavior: New Directions For Teaching and Learning, No. 77, Spring, Jossey-Bass Publishers.

Walker, H. M., Colvin, G., and Ramsey, E.(1995). Antisocial Behavior in school: strategies and Best practices. Pacific Grove, CA: Brooks/cole.

Witt, J. C., Daly, E. M., \& Noell, G. (2000). Functional assessments: A step-by-step guide to solving academic and behavior problems.

Copyrights

Copyright for this article is retained by the author(s), with first publication rights granted to the journal.

This is an open-access article distributed under the terms and conditions of the Creative Commons Attribution license (http://creativecommons.org/licenses/by/4.0/). 